\title{
IMPROVEMENTS OF VEHICLE FUEL ECONOMY USING MECHANICAL REGENERATIVE BRAKING
}

\author{
Alberto Boretti \\ University of Ballarat, Ballarat, Australia
}

Copyright (C) 2010 SAE International

\begin{abstract}
Improvements of fuel economy of passenger cars and light and heavy duty trucks are being considered using a flywheel energy storage system concept to reduce the amount of mechanical energy produced by the thermal engine recovering the vehicle kinetic energy during braking and then assisting torque requirements. The mechanical system has an overall efficiency over a full regenerative cycle of about $70 \%$, about twice the efficiency of battery-based hybrids rated at about $36 \%$. The technology may improve the vehicle fuel economy and hence reduced $\mathrm{CO}_{2}$ emissions by more than $30 \%$ over driving cycles characterized by frequent engine start/stop, and vehicle acceleration, brief cruising, deceleration and stop.
\end{abstract}

\section{KERS FUNDAMENTALS}

It is a fundamental of physics that transforming energy from one form to another inevitably introduces significant losses. This explains why the efficiency of battery-based hybrids is so low for a regenerative braking cycle. When a battery is involved, there are four efficiency reducing transformations in each regenerative braking cycle. (1) Kinetic energy is transformed into electrical energy in a motor/generator, (2) the electrical energy is transformed into chemical energy as the battery charges up, (3) the battery discharges transforming chemical into electrical energy, (4) the electrical energy passes into the motor/generator acting as a motor and is transformed once more into kinetic energy. The four energy transformations reduce the overall level of efficiency. If the motor/generator operates at $80 \%$ efficiency under peak load, in and out, and the battery charges and discharges at $75 \%$ efficiency at high power, the overall efficiency over a full regenerative cycle is only $36 \%$.

The ideal solution is to avoid all four of the efficiency reducing transformations from one form of energy to another by keeping the vehicle's energy in the same form as when the vehicle starts braking when the vehicle is back up to speed. This can be done using high-speed flywheels, popular in space and uninterruptible power supplies for computer systems, but novel in ground vehicles. For the space and computer applications, high-speed motor/generators are used to add and remove energy from the flywheels. In ground vehicles, more efficient mechanical, geared systems are preferred. A mechanically driven flywheel system has losses, due to friction in bearings and windage effects, which make it less efficient than a battery-based system in storing energy for long times. Over the much shorter periods required in cut-and-thrust traffic, a mechanically driven flywheel is much more effective, providing an overall efficiency over a full regenerative cycle of more than $70 \%$, almost twice the value of battery-based hybrids.

Almost every vehicle with a manual transmission is already fitted with a flywheel to smooth the flow of power from the engine and to provide a small store of energy to help prevent stalling on launch. Toy cars use a small flywheel geared up to spin fast enough to provide spectacular scale performance. The geared high-speed flywheel concept is now applied to full-sized cars, trucks and buses. The result is a dramatic improvement in fuel economy, at lower cost, without sacrificing acceleration. Subject of the paper is to compute through vehicle simulations the improvements in fuel efficiency over a driving cycle recovering the braking energy with a mechanically driven flywheel to stop the thermal engine at idle, during braking and during accelerations when energy is available in the flywheel therefore reducing the supply of fuel energy to power the vehicle.

The fuel economy can be increased by reducing the amount of mechanical energy to be provided by the thermal engine recovering the braking energy and shutting down the engine during decelerations, at rest and during the portion of the acceleration following a deceleration that can be covered by the energy stored.

Considering the theoretical advantages of storing braking mechanical energy with a much more efficient, simple and lighter mechanical device, and the recent improvements in kinetic energy recovery systems (KERS) for F1 applications [1 to 11], improvements in fuel economy are being considered using a KERS to recover the braking energy and to buffer the thermal engine. 


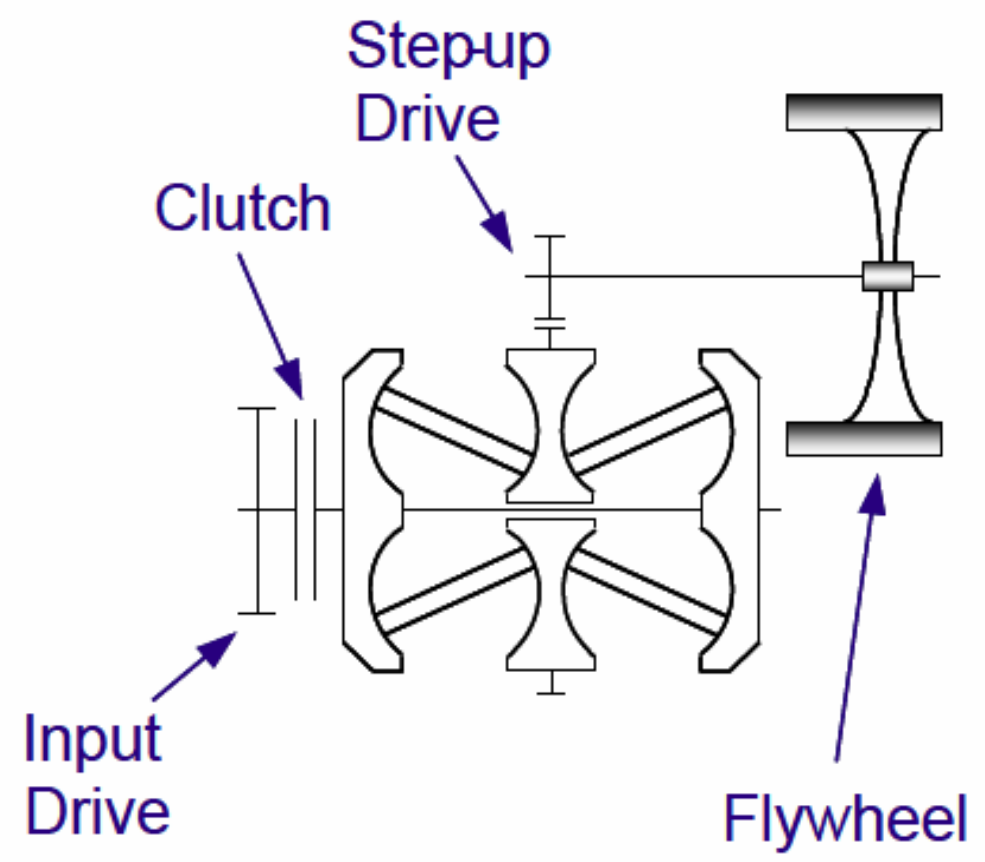

Figure 1 - Schematic flywheel mechanical hybrid system (from [7, 9, 10]).

Figure 1 describes a schematic flywheel mechanical hybrid system (from [7, 9, and 10]). KERS store energy under vehicle braking and return it under vehicle acceleration. The system utilizes a flywheel as the energy storage device and a Continuously Variable Transmission (CVT) to transfer energy to and from the driveline. Transfer of vehicle kinetic energy to flywheel kinetic energy reduces the speed of the vehicle and increases the speed of the flywheel. Transfer of flywheel kinetic energy to vehicle kinetic energy reduces the speed of the flywheel and increases the speed of the vehicle. The CVT is used because ratios of vehicle and flywheel speed are different during a braking or acceleration event. A clutch allows disengagement of the flywheel when not used.

For a traditional power train, the driveline equation balances vehicle side output torque from clutch or torque converter with inertia torque of the entire driveline and vehicle and the effective torque of the retarding forces on the vehicle, namely aerodynamic, rolling resistance and grade forces:

$$
\begin{aligned}
& \tau_{d i v, v}=\left[I_{\text {trans } 1}+\frac{I_{\text {trans } 2}}{R_{t}^{2}}+\frac{I_{d s h}}{R_{t}^{2}}+\frac{I_{a x l}}{R_{d}^{2} R_{t}^{2}}+\frac{M_{v e h} r_{w h l}^{2}}{R_{d}^{2} R_{t}^{2}}\right] \frac{d \omega_{d v v}}{d t} \\
- & {\left[\frac{I_{\text {trans } 2}}{R_{t}^{3}}+\frac{I_{d s h}}{R_{t}^{3}}+\frac{I_{a x l}}{R_{d}^{2} R_{t}^{3}}+\frac{M_{v e h} r_{w h l}^{2}}{R_{d}^{2} R_{t}^{3}}\right] \omega_{d r v} \frac{d R_{t}}{d t} } \\
+ & {\left[\frac{F_{a e r}+F_{\text {rol }}+F_{\text {grd }}}{R_{d} R_{t}}\right] r_{w h l} }
\end{aligned}
$$

Where $\tau_{d r v, e}$ is the engine side torque of clutch or torque converter, $\tau_{d r v, v}$ the vehicle side torque of clutch or torque converter. $\omega_{d r v}$ the driveline speed on vehicle side of clutch or torque converter, $\mathrm{I}_{\boldsymbol{a x l}}$ the axle moment of inertia, $\mathbf{I}_{d s h}$ the driveshaft inertia, $\mathbf{I}_{\text {trans } 1}$ the input side transmission moment of inertia, $\mathbf{I}_{\text {trans } 2}$ the output side transmission moment of inertia, $\mathbf{M}_{v e h}$ the vehicle mass, $\mathbf{r}_{w h l}$ the wheel radius, $\mathbf{F}_{a e r}$ the aerodynamic force on vehicle, $\mathbf{F}_{r o l}$ the rolling resistance force on vehicle, $\mathbf{F}_{g r d}$ the grade force on vehicle, $\mathbf{R}_{t}$ the transmission ratio, $\mathbf{R}_{\boldsymbol{d}}$ the final drive ratio, $\mathbf{t}$ the time. This equation and the engine equation of motion, this latter balancing engine brake torque with engine inertia torque and engine side load torque from the clutch or torque converter, determine the operating points (torque and speed) of the engine. Braking at the wheels may be assimilated to a torque component, or even better to a slipping clutch component. Either way, braking at the wheels dissipates the kinetic energy of the vehicle that is therefore lost.

KERS store energy under vehicle braking and return it under vehicle acceleration. The system utilises a flywheel as the energy storage device and a Continuously Variable Transmission (CVT) to transfer energy to and from the driveline. Transfer of vehicle kinetic energy to flywheel kinetic energy reduces the speed of the vehicle and increases the speed of the flywheel. Transfer of flywheel kinetic energy to vehicle kinetic energy reduces the speed of the flywheel and increases the speed of the vehicle. The CVT is used because ratios of vehicle and flywheel speed are different during a braking or acceleration event. A clutch allows disengagement of the flywheel when not used. 
The kinetic energy of the flywheel is $\mathbf{E}=1 / 2 \cdot \mathbf{J} \cdot \boldsymbol{\omega}^{2}$ where $\mathbf{J}$ is the moment of inertia of the flywheel and $\boldsymbol{\omega}$ the angular velocity. The flywheel has a moment of inertia $\mathbf{J}=1 / 2 \cdot \mathbf{m} \cdot\left(\mathbf{r}_{1}^{2}-\mathbf{r}_{2}^{2}\right)$, where $\mathbf{m}$ is the mass, $\mathbf{r}_{1}$ the outer radius and $\mathbf{r}_{2}$ the inner radius. It is possible to use low speed high inertia flywheels, or high speed low inertia flywheels, to store same energy. F1 systems use a very light weight composite flywheel, made up of a carbon fibre filament wound rim surrounding a steel hub, rotating at very high speed in a vacuum [9-15]. This design has proved to be quite effective but also quite expensive to produce, with other solutions being considered for mass production [16].

The dynamic behaviour of a rigid flywheel rotor in bearings on elastic supports (elastic to account for finite stiffness of bearings, shaft and structures), allows two modes of operation, sub-critical with flywheel speed ranging from zero to a speed that is safely below the first critical speed, and super-critical with flywheel speed ranging between two consecutive critical speeds. The first mode of operation permits low energy storage, and only the second mode for high energy storage is considered.

Wheel braking is therefore partially replaced by increasing the flywheel speed of rotation from a low to a high value, thus storing part of the available kinetic energy. This stored kinetic energy is then used to reaccelerate the vehicle reducing the flywheel speed of rotation from a high to a low value.

System efficiency is a key area where the mechanical hybrid system excels over the electric hybrid. Battery based electric hybrid systems require a number of energy conversions each with corresponding efficiency losses. On reapplication of the energy to the drive line, the global energy conversion efficiency is $31-34 \%$ [8]. The mechanical hybrid system storing energy mechanically in a rotating fly wheel eliminates the various energy conversions and provides a global energy conversion efficiency exceeding $70 \%$, more than twice the efficiency of an electric system [8]. However, it is to be pointed out that KERS may store energy efficiently only over a small time interval. Therefore more complex buffering strategies where the thermal engine operation is virtually decoupled by the road load that are possible with electric hybrid vehicles are not possible with mechanical hybrid vehicles.

Recovery of the braking energy reduces the amount of thermal energy requested to power the vehicle and reduce the time the thermal engine is on. Efficiency of KERS energy storage and release, maximum amount of energy being stored, energy loss in start/stop of engine and timing of deceleration and acceleration processes and therefore efficiency of the control play a dominant role in determining the best configuration of a KERS assisted power train. Using optimized strategies $\mathrm{CO}_{2}$ and fuel consumption reductions of over $20 \%$ are possible on the NEDC cycle and more than $30 \%$ is possible in real world conditions [1].

Friction braking is used in conjunction with mechanical regenerative braking to bring the vehicle to a complete halt and as a necessary back-up in the event of failure. In case of power on some wheels as in 2 Wheels Drive (2WD) cars, regenerative braking only applies to such wheels, and friction braking on the other wheels is necessary to provide controlled braking under difficult conditions. The amount of energy that can be stored is limited, and no regenerative braking effect can occur if the flywheel is already spinning close at maximum speed. Under emergency, the braking force exerted must be the maximum allowed by the friction between the wheels and the surface without slipping from the vehicle's maximum speed down to zero. The maximum force available for acceleration is usually much less than this. For all these reasons, friction and regenerative braking have to be coupled together to produce the desired total braking output.

The Flybrid specifications for the 2009 Formula 1 KERS $[6-8,10]$ are presented in Table A1 in Appendix as a reference. The system is light and compact and does not present major challenges for installation in a passenger car. While in the F1 KERS a vacuum pump is not required and hermetic vacuum seal is sealed when stationary, a vacuum pump is needed in passenger car or truck applications. Passenger car applications require different maximum power and energy storage capacity, and may allow increased weight and dimensions of the assembly without compromising the vehicle packaging and handling. Truck applications may be more complicated because of the much larger energy storage capacity needed. Vehicle packaging and handling may therefore require special consideration for truck applications.

\section{PASSENGER CAR CYCLES}

Fuel economy and emission compliance is measured over test cycles. The ECE+EUDC cycle is a test cycle performed on a chassis dynamometer used for emission certification of light duty vehicles in Europe [EEC Directive 90/C81/01]. The entire cycle includes four ECE segments, repeated without interruption, followed by one EUDC segment. Before the test, the vehicle is allowed to soak for at least 6 hours at a test temperature of $20-30^{\circ} \mathrm{C}$. It is then started and the emission sampling begins at the same time. This cold-start procedure is also referred to as the New European Driving Cycle (NEDC). The ECE cycle is an urban driving cycle, also known as UDC. It was devised to represent city driving conditions, e.g. in Paris or Rome. It is characterized by low vehicle speed, low engine load, and low exhaust gas temperature. The EUDC (Extra Urban Driving Cycle) segment has been added after the fourth ECE cycle to account for more aggressive, high speed driving modes. The maximum speed of the EUDC cycle is $120 \mathrm{~km} / \mathrm{h}$. An alternative EUDC cycle for low-powered vehicles has been also defined with a maximum speed limited to $90 \mathrm{~km} / \mathrm{h}$. 
Figure 2 presents the prescribed velocity of the car. Table 1 summarizes the parameters for both the ECE and EUDC cycles. The NEDC velocity schedule uses four ECE segments followed by one EUDC segment from a cold start.

\begin{tabular}{||c|c|c||}
\hline Characteristics & ECE & EUDC \\
\hline Distance $[\mathrm{km}]$ & $4 \times 1.013=4.052$ & 6.955 \\
\hline Duration $[\mathrm{s}]$ & $4 \times 195=780$ & 400 \\
\hline Average Speed $[\mathrm{km} / \mathrm{h}]$ & 18.7 (with idling) & 62.6 \\
\hline Maximum Speed $[\mathrm{km} / \mathrm{h}]$ & 50 & 120 \\
\hline
\end{tabular}

Table 1 - Main characteristics of ECE and EUDC sectors.

Figure 3 presents vehicle and flywheel speed for a passenger car over the New European Driving Cycle. Every deceleration of the car produces an acceleration of the flywheel from a minimum speed of rotation to a larger speed of rotation following the transfer of energy wheels to flywheel. The speed of rotation of the flywheel is then reduced back to the minimum speed as soon as the flywheel energy is transferred back to the wheels to power the vehicle for acceleration or cruise. The design of the actual flywheel may change this behaviour.

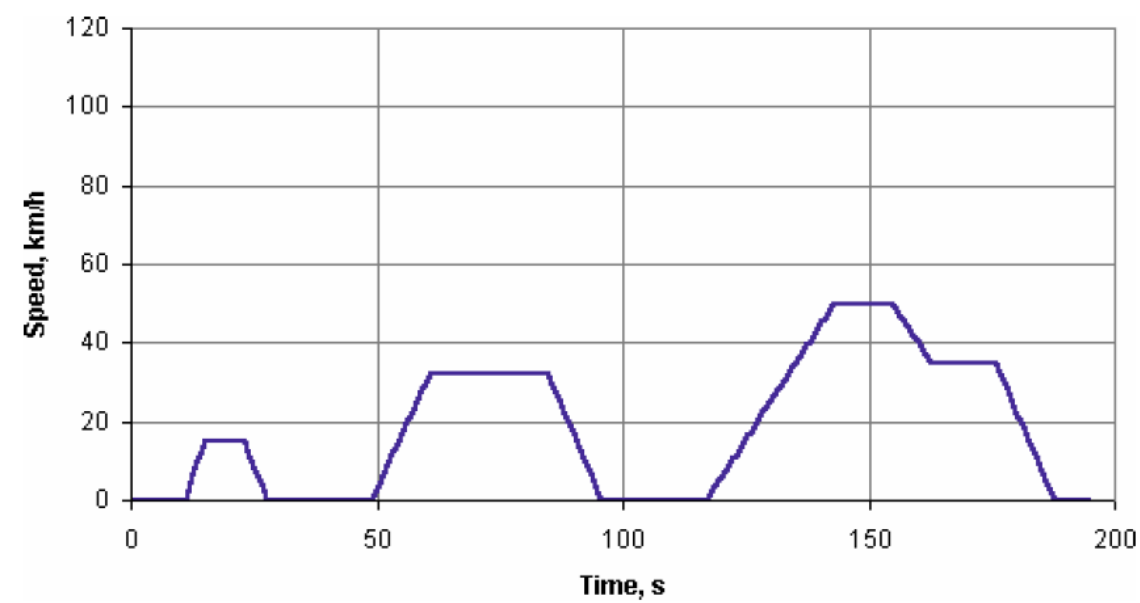

Figure 2.a-ECE velocity schedule.

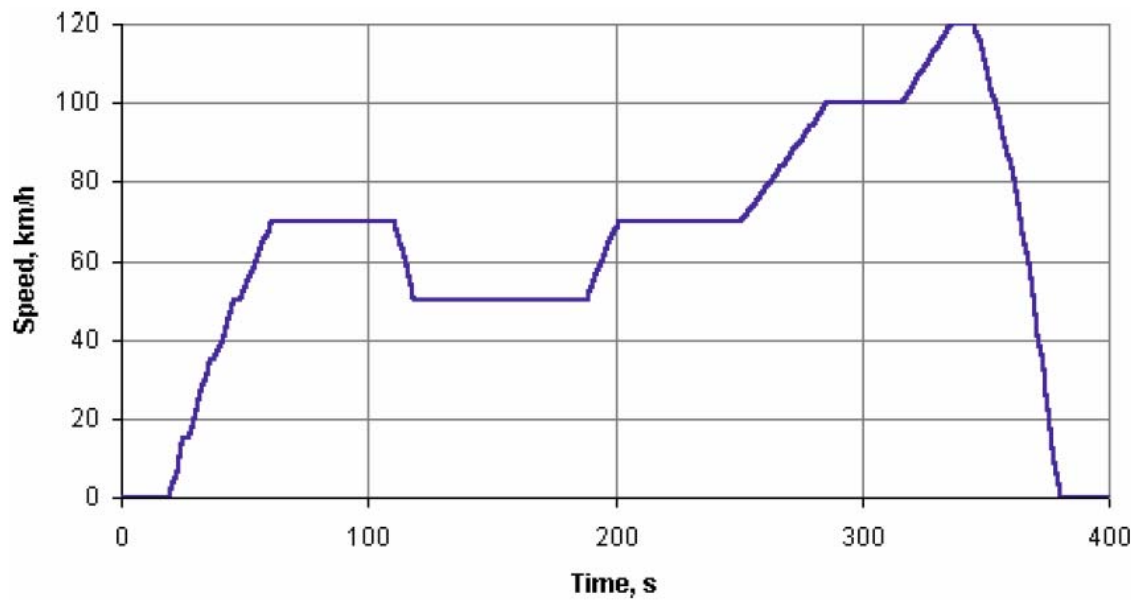

Figure 2.b - EUDC velocity schedule. 


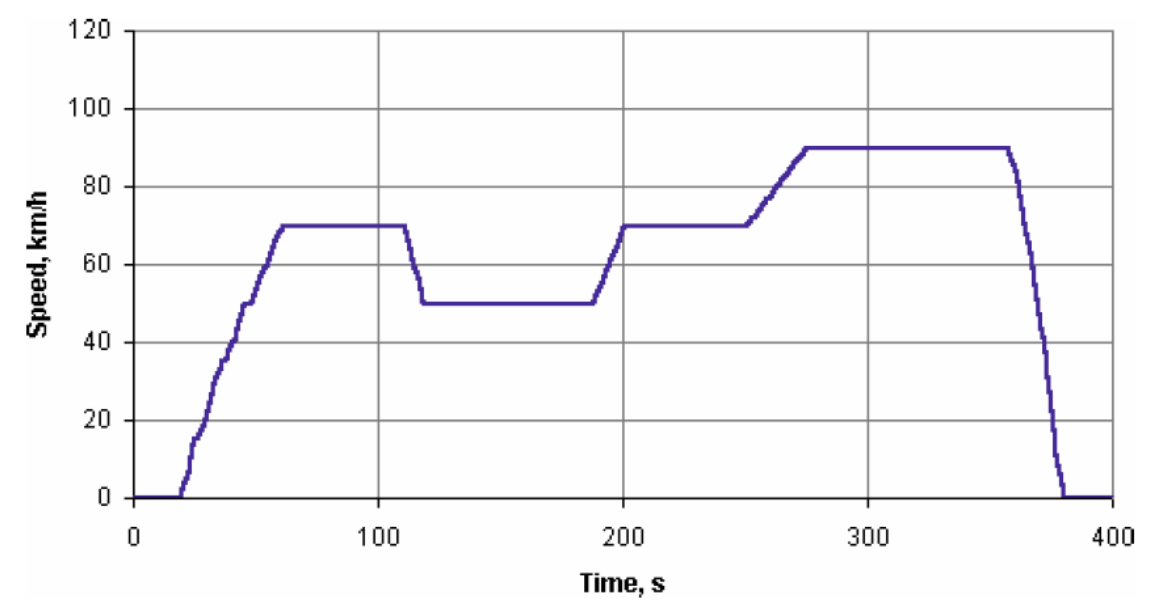

Figure 2.c - EUDC velocity schedule for low powered vehicles.
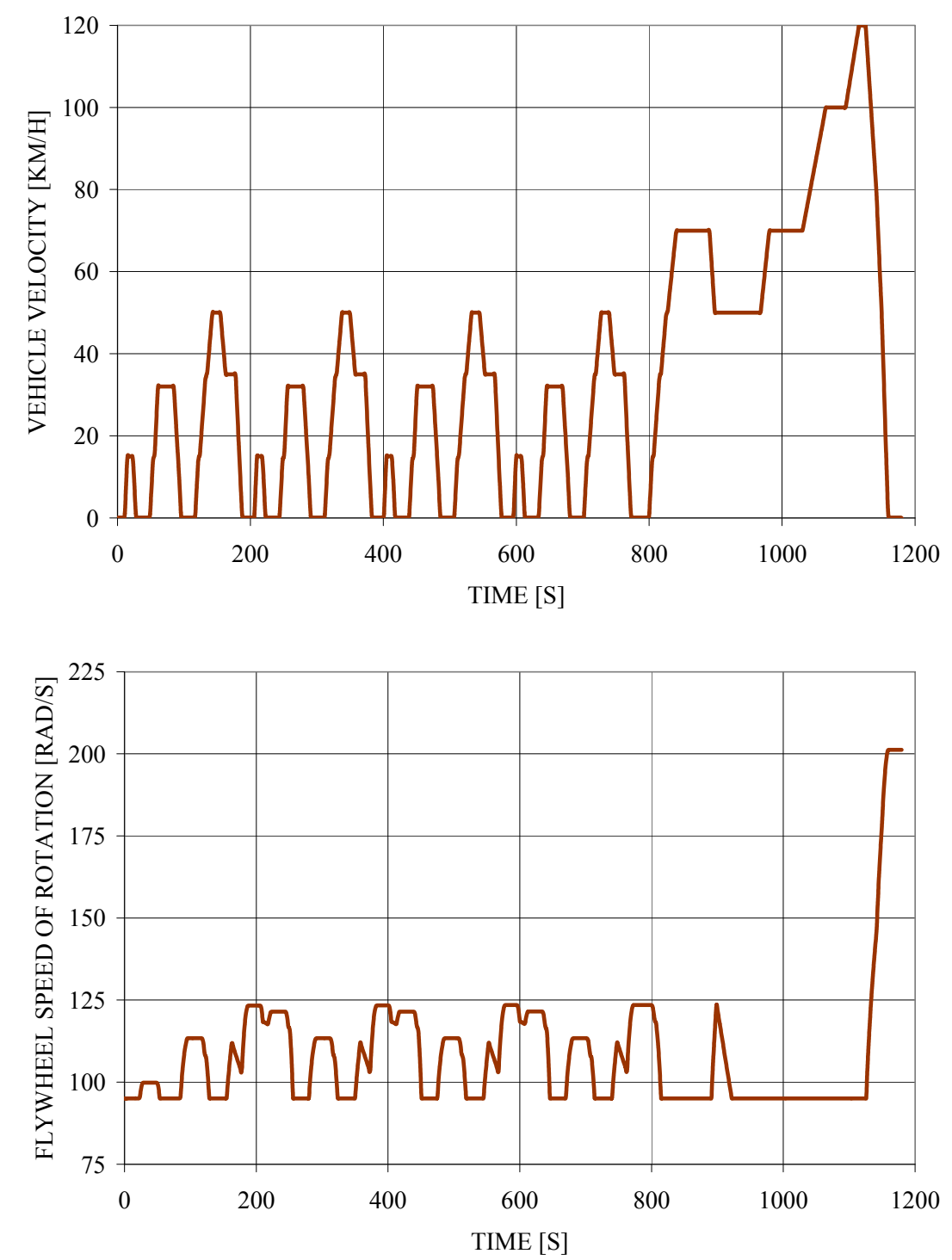

Figure 3 - Vehicle velocity and flywheel speed of rotation for a passenger car over the NEDC driving cycle. 


\section{FULL SIZE GASOLINE PASSENGER CAR WITH KERS}

Simulations have then been performed for a large D class, full size passenger car. The car is powered by a naturally aspirated, 4 litres, and stoichiometric gasoline engine. Basic data of the engine and the vehicle are presented in Tables 2 and 3 . The shift strategy is set to minimize fuel use over the NEDC. Figure 4 presents the gearbox cascade diagram. This picture displays the tractive load diagram for the vehicle system at each drive ratio vs. the combined aerodynamic and tyre loads and vehicle speed. Figure 5 presents the Brake Specific Fuel Consumption (BSFC) vs. Brake Mean Effective Pressure (BMEP) and engine speed. The brake specific fuel consumption (BSFC) is a measure of fuel efficiency within a shaft reciprocating engine. It is the rate of fuel consumption divided by the power produced. BSFC allows the fuel efficiency of different reciprocating engines having same fuel to be directly compared. The brake specific fuel consumption charts are power train oriented data needed to compute the vehicle fuel efficiency. These values are computed with a validated engine model (WAVE, [13]).

Results of vehicle fuel economy over the NEDC have then been obtained with a validated vehicle model (Lotus Vehicle [14]). The baseline configuration with the 4 litre engine requires $0.439 \mathrm{~kg}$ of fuel to cover the $4.052 \mathrm{~km}$ of the urban sector, and $0.850 \mathrm{~kg}$ of fuel to cover the full cycle. Considering a density of $0.75 \mathrm{~kg} /$ litre, this corresponds to a fuel economy of 14.4 litres $/ 100 \mathrm{~km}$ over the urban sector, and 10.3 litres $/ 100 \mathrm{~km}$ over the full cycle. The large naturally aspirated engine works the most part of the driving cycle at low speed and BMEP, more often around $1500 \mathrm{rpm}$ and $1 \mathrm{bar}$. The large amount of energy used to accelerate the vehicle is then lost decelerating the vehicle. The operation of the engine at idle or very low speed and BMEP is very inefficient.

Considerable improvements for this vehicle may be obtained recovering the braking kinetic energy with a KERS and stopping the engine during large portions of the cycle when the KERS provides the energy needed. Very preliminary computations have been performed assuming reference values [1-12] for maximum energy storage in KERS, energy penalties for start/stop, efficiency of storage and recovery of energy, energy requested to run ancillary loads, new ancillary loads introduced by KERS and engine warm-up profile.

The engine is shut down during a deceleration of the vehicle to stop, and it is restarted during the following acceleration when the kinetic energy recovered during the braking is fully consumed to re-accelerate the vehicle, run the ancillaries with engine shut-down, and re-start the engine. The efficiency of the charging and discharging process is supposed to be $70 \%$. Differences in the warm-up profile of the engine (engine metal, coolant and oil temperatures vs. time) with and without KERS are neglected.

The configuration with the 4 litre engine and KERS requires $0.27 \mathrm{~kg}$ of fuel to cover the $4.052 \mathrm{~km}$ of the urban sector, and $0.64 \mathrm{~kg}$ of fuel to cover the full cycle. This corresponds to a fuel economy of 8.8 litres/100 km over the urban sector (fuel saving of more than $35 \%$ ), and 7.7 litres $/ 100 \mathrm{~km}$ over the full cycle (fuel saving of $25 \%$ ). The engine may be stopped $50 \%$ of the time with KERS. Part of the energy recovered is lost in the start-stop of the engine.

\begin{tabular}{||c|c||}
\hline \hline Number of Cylinders & 6 \\
\hline Bore [mm] & 92.2 \\
\hline Stroke [mm] & 99.3 \\
\hline Compression ratio & 10.5 \\
\hline Swept Volume [1] & 4 \\
\hline
\end{tabular}

Table 2 - Basic engine data, full size passenger car.

\begin{tabular}{|c|c|}
\hline Weight $[\mathrm{kg}]$ & 1810 \\
\hline Frontal Area $\left[\mathrm{m}^{2}\right]$ & 2.250 \\
\hline Drag Coefficient & 0.298 \\
\hline Tyre Rolling Radius [m] & 0.316 \\
\hline Final Drive Ratio & 2.73 \\
\hline Gearbox & Automatic \\
\hline Number of ratios & 5 \\
\hline Gear. 1 Ratio & 3.22 \\
\hline Gear. 2 Ratio & 2.29 \\
\hline Gear. 3 Ratio & 1.55 \\
\hline Gear. 4 Ratio & 1 \\
\hline Gear. 5 Ratio & 0.75 \\
\hline
\end{tabular}

Table 3 - Basic vehicle data, full size passenger car. 


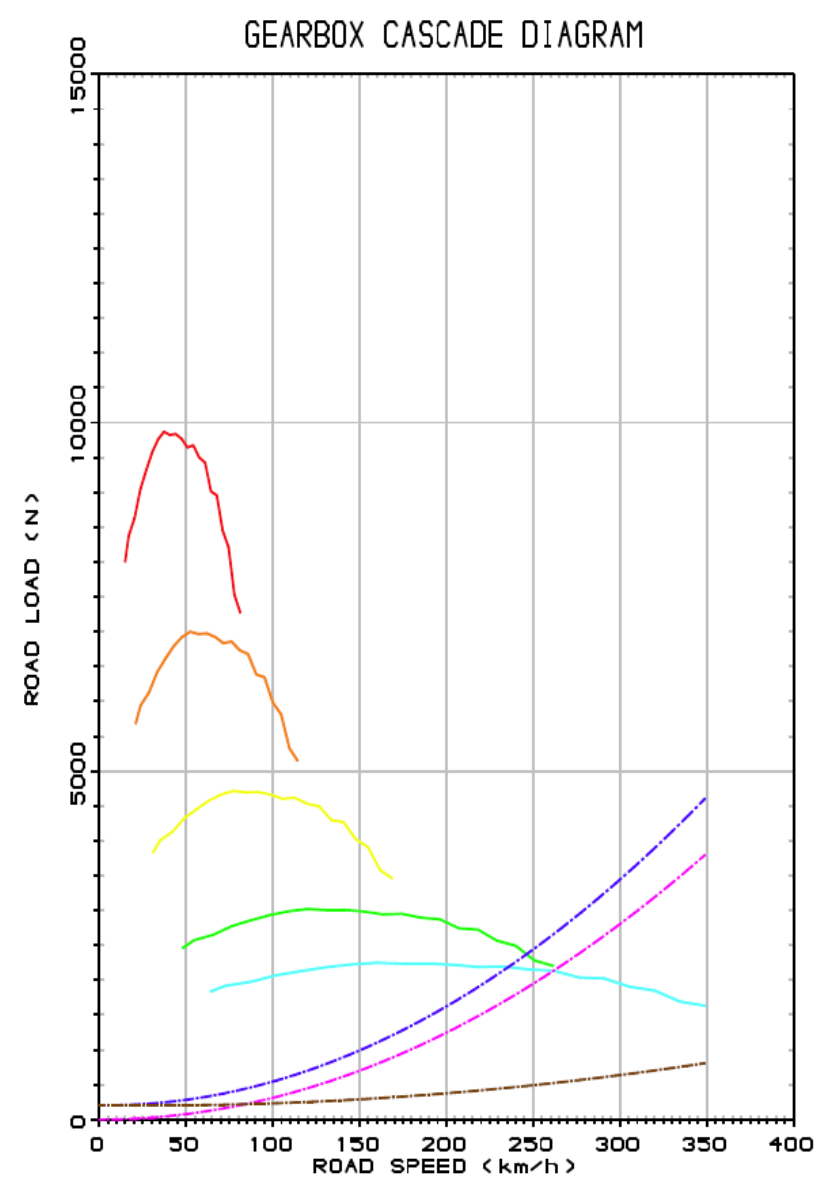

Table 4 - Tractive load diagram for the vehicle system at each drive ratio vs. the combined aerodynamic and tyre loads and vehicle speed (full size gasoline passenger car).

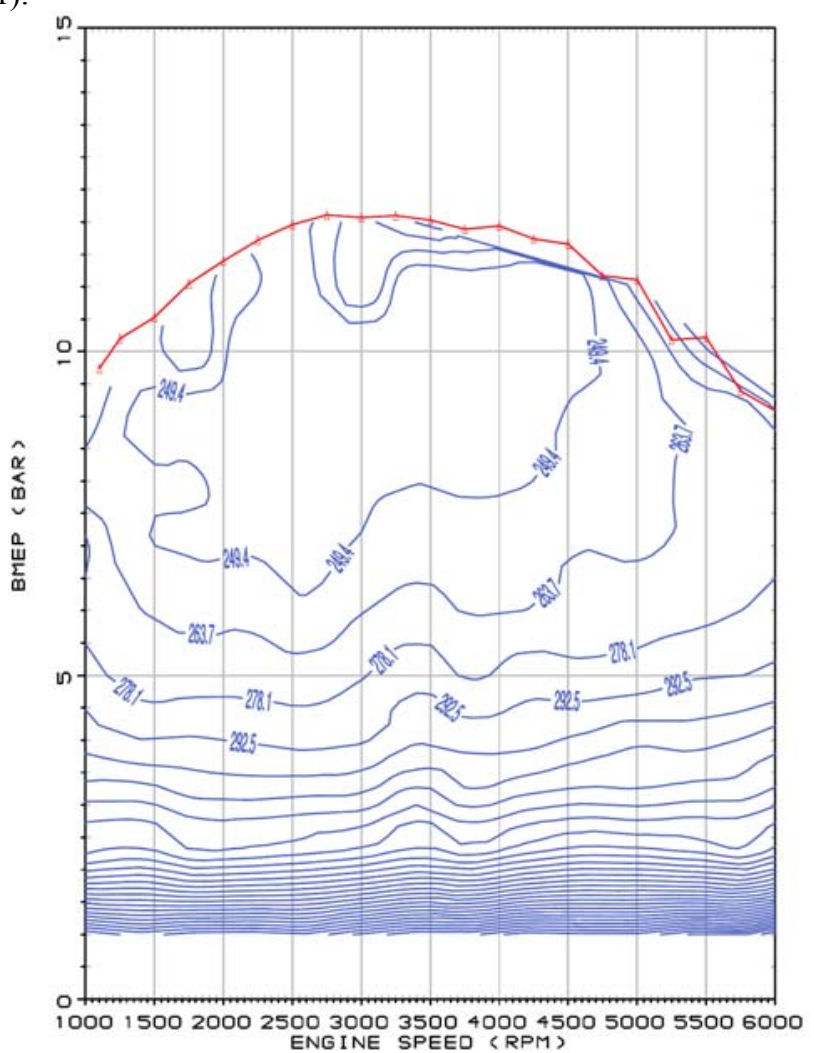

Figure 5 - Computed brake specific fuel consumption (in $\mathrm{g} / \mathrm{kWh}$ ) map for a 4 litre gasoline engine. 
It has to be pointed out that the vehicle stops from high speed at the end of the NEDC with immediate engine turn off. This waste all the energy stored in the KERS following the sharp deceleration. Clearly the end of the NEDC cycle is very far from the real life operation of the car, and therefore real life benefits of KERS may be guessed to more than $30 \%$ better fuel economy.

Further improvements may follow downsizing of the internal combustion engine thanks to the boosting provided by KERS during accelerations. The thermal engine in a conventional car or truck is a compromise having to provide sufficient power during full load strong accelerations, then part load high fuel conversion efficiency when the vehicle is cruising. The displacement needed for full load strong accelerations is a handicap for the cruising part load conversion efficiency. Availability of mechanical energy in the KERS to boost accelerations may permit downsizing of the thermal engine therefore further improving the fuel economy.

The displacement effect shifts up by a factor equal to the displacement ratio the operating BMEP. In hypothesis the brake specific fuel consumption map is the same for both the original and the downsized engine, reduction of the displacement of the engine from 4 to 3.3 litres produce an improved fuel economy of about $10 \%$ (brake specific fuel consumptions $10 \%$ better on average). This is due to the very low part load efficiencies at very low BMEP of the throttle-controlled stoichiometric large gasoline engine. The configuration with the 3.3 litre downsized engine and the KERS reduces the fuel usage to 7 litres per $100 \mathrm{~km}$ (fuel saving of $33 \%$ ).

In terms of miles per gallon US, the baseline configuration with a 4 litre engine and no KERS has a full cycle fuel economy of 22.83 mpgUS, the adoption of KERS increases the fuel economy to $30.54 \mathrm{mpgUS}$, and the downsizing of the engine to 3.3 litres with KERS further increases the fuel economy to 33.6 mpgUS.

\section{COMPACT SIZE PASSENGER CAR WITH KERS}

KERS have been coupled so far to gasoline powered engines in large sedans to provide improvements of fuel economy of $20-25 \%$. Smaller improvements in fuel consumption but better then hybrids fuel economies may be obtained by coupling KERS to small, turbocharged Diesel engine.

Simulations have then been performed for a $\mathrm{C}$ class, compact passenger car. The car is powered by a 1.6TDI Diesel engine. Basic data of the engine and the vehicle are presented in Tables 4 and 5. Figure 6 presents the gearbox cascade diagram, tractive load at each drive ratio vs. the combined aerodynamic and tyre loads and vehicle speed. Figure 7 presents the Brake Specific Fuel Consumption (BSFC) vs. Brake Mean Effective Pressure (BMEP) and engine speed. These values are computed with a validated engine model (WAVE, [13]). The shift strategy is set to minimize fuel use over the NEDC.

Results of vehicle fuel economy over the NEDC have then been obtained with a validated vehicle model (Lotus Vehicle, [14]). The baseline configuration with the $1.6 \mathrm{TDI}$ engine requires $0.16 \mathrm{~kg}$ of fuel to cover the $4.052 \mathrm{~km}$ of the urban sector, and $0.35 \mathrm{~kg}$ of fuel to cover the full cycle.

\begin{tabular}{||c|c||}
\hline \hline Number of Cylinders & 4 \\
\hline Bore [mm] & 79.50 \\
\hline Stroke [mm] & 80.50 \\
\hline Compression ratio & 16.5 \\
\hline Swept Volume [1] & 1.5984 \\
\hline
\end{tabular}

Table 4 - Basic engine data.

\begin{tabular}{|c|c|}
\hline Weight $[\mathrm{kg}]$ & 1336 \\
\hline Frontal Area $\left[\mathrm{m}^{2}\right]$ & 2.2 \\
\hline Drag Coefficient & 0.298 \\
\hline Tyre Rolling Radius [m] & 0.3080 \\
\hline Final Drive Ratio & 3.389 \\
\hline Gearbox & Manual \\
\hline Number of ratios & 5 \\
\hline Gear. 1 Ratio & 3.7780 \\
\hline Gear. 2 Ratio & 1.9440 \\
\hline Gear. 3 Ratio & 1.1850 \\
\hline Gear. 4 Ratio & 0.8160 \\
\hline Gear. 5 Ratio & 0.6250 \\
\hline
\end{tabular}

Table 5 - Basic vehicle data. 


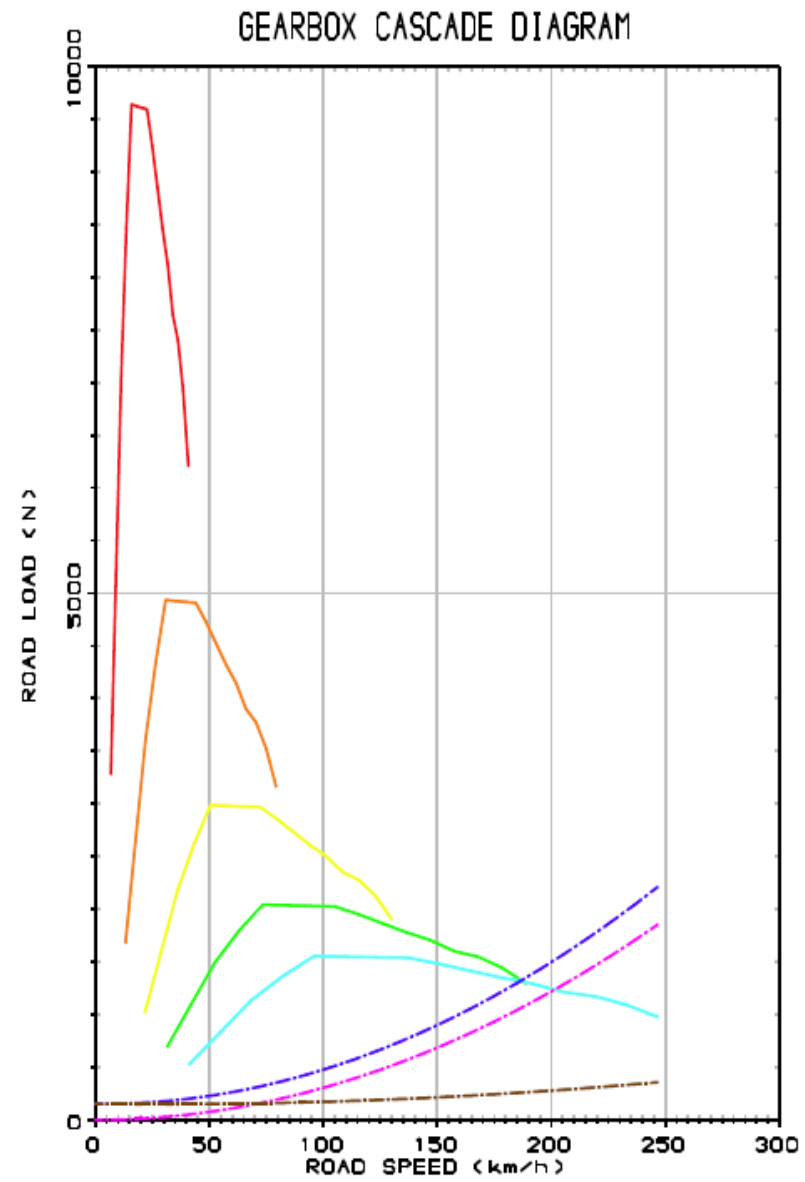

Table 6 - Tractive load diagram for the vehicle system at each drive ratio vs. the combined aerodynamic and tyre loads and vehicle speed (compact size diesel passenger car)

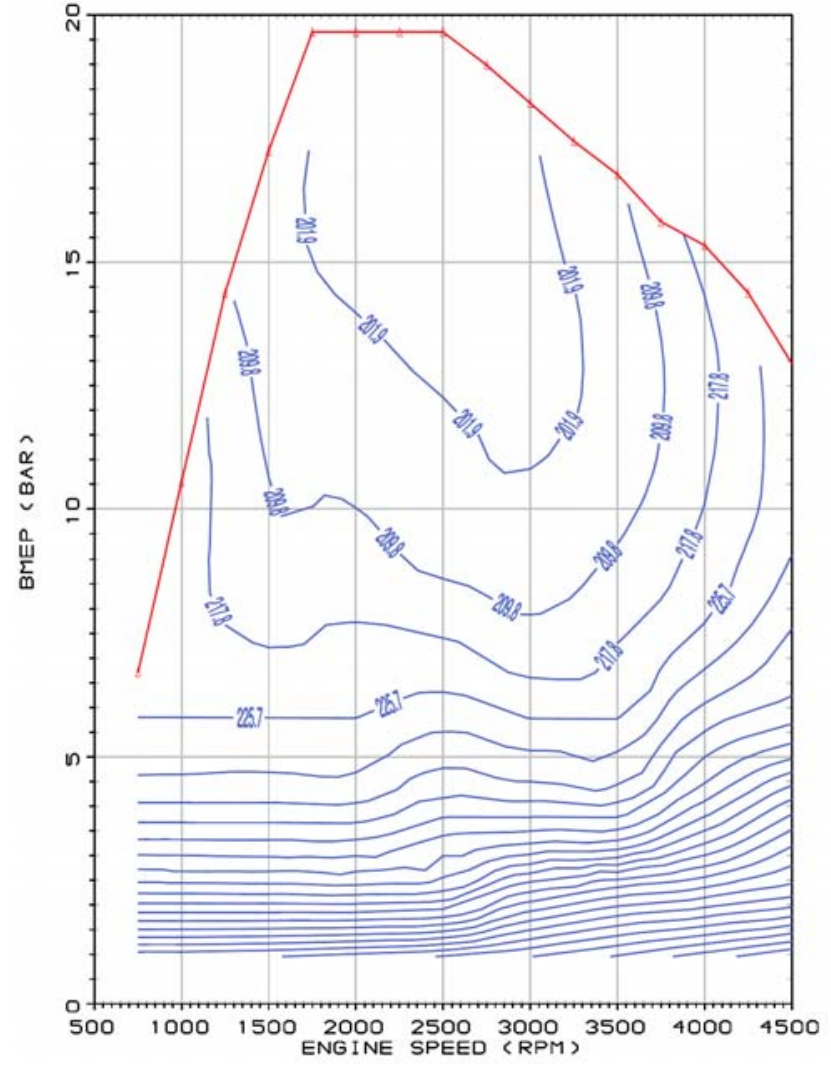

Figure 7 - Computed brake specific fuel consumption (in $\mathrm{g} / \mathrm{kWh}$ ) map for the 1.6 TDI Diesel engine. 
Considering a density of $0.84 \mathrm{~kg} /$ litre, this corresponds to a fuel economy of 4.7 litres $/ 100 \mathrm{~km}$ over the urban sector, and 3.8 litres/100 $\mathrm{km}$ over the full cycle. The small turbocharged engine works the most part of the driving cycle at medium speed and high BMEP. The larger efficiencies of the Diesel both top and part load resulting from the higher compression ratio, the turbo charging, the lean operation and the non throttled load control by quantity of fuel injected permits operation with much larger fuel efficiencies. However, a still significant amount of energy used to accelerate the vehicle is then lost decelerating the vehicle.

Preliminary computations have then been performed modelling a modified version with KERS of the vehicle. Reference values are again assumed for maximum energy storage in KERS, energy penalties for start/stop, efficiency of storage and recovery of energy, energy requested to run ancillary loads, new ancillary loads introduced by KERS and engine warm-up profile. The engine is shut-off during decelerations, and it is restarted during the following acceleration when the kinetic energy recovered during the braking is fully consumed.

The configuration with the 1.6TDI engine and KERS requires $0.12 \mathrm{~kg}$ of fuel to cover the $4.052 \mathrm{~km}$ of the urban sector, and $0.29 \mathrm{~kg}$ of fuel to cover the full cycle. This corresponds to a fuel economy of 3.5 litres/100 km over the urban sector (fuel saving of $25 \%$ ), and 3.2 litres $/ 100 \mathrm{~km}$ over the full cycle (fuel saving of 17\%). The engine may be stopped near $50 \%$ of the time with KERS. Part of the energy recovered is lost in the start-stop of the engine.

Further improvements may follow downsizing of the internal combustion engine thanks to the boosting provided by KERS during accelerations. The displacement effect shifts up by a factor equal to the displacement ratio the operating BMEP. In hypothesis the brake specific fuel consumption map is the same for both the original and the downsized engine, reduction of the displacement of the engine from 1.6 to 1.2 litre produce an improved fuel economy of about $4 \%$ (brake specific fuel consumptions $4 \%$ better on average).

This is due to the smaller improvements in efficiency changing the load throttle less by quantity of fuel injected as typical of Diesel. The configuration with the downsized 1.2TDI engine and the KERS reduces the fuel usage to 3.04 litres per $100 \mathrm{~km}$.

The configuration with the 1.6TDI Diesel engine and KERS reduces the fuel usage to 3.16 litres per $100 \mathrm{~km}$, corresponding to a production of $82.4 \mathrm{~g}$ of $\mathrm{CO}_{2}$ per km. These $\mathrm{CO}_{2}$ values are $7 \%$ better than those of today's best hybrid electric vehicle. Downsizing the engine to 1.2 litres, the fuel consumption is reduced to 3.04 litres per $100 \mathrm{~km}$, corresponding to a production of $79.2 \mathrm{~g}$ of $\mathrm{CO}_{2}$ per $\mathrm{km}$. These $\mathrm{CO}_{2}$ values are $11 \%$ better than those of today's best hybrid electric vehicle.

Clearly, the end of the NEDC cycle with the stop of the vehicle from high speed and immediate engine turn off is very far from the real life operation of the car. Real life benefits of KERS may therefore be guessed to be even more fuel saving.

In terms of miles per gallon US, the baseline configuration with a 1.6 litre engine and no KERS has a full cycle fuel economy of 61.9 mpgUS, the adoption of KERS increases the fuel economy to $73.5 \mathrm{mpgUS}$, and the downsizing of the engine to 1.2 litres with KERS further increases the fuel economy to 77.4 mpgUS.

\section{HEAVY DUTY VEHICLE CYCLES}

Current regulations do not require complete heavy-duty diesel and gas vehicles to be chassis certified, instead requiring certification of their engines [15-18]. Many driving cycles have been proposed to represent real world driving for emissions and fuel consumption testing [19-24]. However, these cycles are not part of current emission regulations and their validity is not globally recognized.

The World-Wide Harmonized Heavy-Duty Certification (WHDC) Procedure applies to Diesel and gas engines (natural gas or LPG) [15-18] tested on engine dynamometers. WHDC is based on the world-wide pattern of real non hybrid heavy commercial vehicle use. From the collected data, two representative test cycles, a transient test cycle (WHTC) with both cold and hot start requirements and a hot start steady state test cycle (WHSC), have been created covering typical driving conditions in the European Union (EU), the United States of America, Japan and Australia. The WHTC and WHSC test procedures reflect world-wide on-road heavy-duty engine operation on vehicles with non-hybrid power trains. Therefore, the benefits KERS may introduce in heavy duty vehicles have to be evaluated on cycles having a limited recognition.

Different drive cycles may be considered following the application, highway line haul, regional haul, local pick up and delivery, neighbourhoods refuse truck, utility service truck, transit bus, intermodal drayage truck. Other options to be considered my include drive cycle load requirements as accessory load, cargo load and power take-off (PTO) and service load. All these cycles have the problem of being really representative of a given application versus broad diversity of actual in-use fleet operations. Large fleets distrust short tests, and more actual duty cycle data is needed to further develop these cycles. Finally, complex cycles will have a lower repeatability than a series of modal tests at steady state.

The Highway Line Haul - EPA or the Highway Line Haul -NESCAUM/SwRI cycles already offer some options to recover the braking energy therefore improving the fuel economy and reducing GHG and possibly other emissions. However, the Local Delivery -Class 4 (Neighbourhood), the Local Delivery -Class 6 (Business), the Neighbourhood Refuse Truck, the Utility Service Truck or the 
Intermodal Drayage Truck cycles and all of the transit bus cycles certainly offer much better opportunities to achieve better fuel economies with KERS.

\section{HEAVY DUTY TRUCK WITH KERS}

In the previous application, KERS have been coupled to both gasoline powered full size and Diesel powered compact size passenger cars, with fuel economy benefits larger in the gasoline rather than in the Diesel option, but however more than $30 \%$ on the ECE sector of the NEDC. Improvements in fuel consumption may also be obtained by coupling KERS to a heavy duty truck powered by a turbocharged Diesel engine.

The truck is a front axle refuse truck powered by an 11TDI Diesel engine with an 8-Speed transmission to the rear axle of Ratios 17.77 Low to 0.71 High. Basic data of the engine and the vehicle are presented in Tables 6 and 7. Figure 8 presents the gearbox cascade diagram, tractive load at each drive ratio vs. the combined aerodynamic and tyre loads and vehicle speed. Figure 9 presents the Brake Specific Fuel Consumption (BSFC) vs. Brake Mean Effective Pressure (BMEP) and engine speed. These values are computed with a validated engine model (WAVE, [13]).

Because of the unavailability of better driving cycles to be considered, first simulations have been performed with a vehicle model (Lotus Vehicle, [14]) over the hot ECE+EUDC cycle, made up of four ECE segments followed by one low speed EUDC segment starting with an hot engine.

However, the high and low speed version of the EUDC, having maximum speed of $120 \mathrm{~km} / \mathrm{h}$ and $90 \mathrm{~km} / \mathrm{h}$ respectively, is not suitable for a heavy duty truck. Therefore, the velocity schedule is redefined introducing a maximum speed of $80 \mathrm{~km} / \mathrm{h}$. The special hot ECE+EUDC velocity scheduled is shown in Figure 10.

The passenger cars use a shift strategy to minimize fuel consumption over a cycle, with shifting obeying a detailed strategy change down - change up given as a function of the vehicle speed. Conversely, the heavy duty truck has a shift strategy set to use the engine within a window of high torque. Shifting therefore obeys a detailed strategy change down - change up given as a function of the engine speed. The shift schedule is set to use the engine in between 1,200 rpm and 1,900 rpm operating points.

The baseline configuration with the 11 TDI engine requires $2.85 \mathrm{~kg}$ of fuel to cover the full cycle. Considering a density of 0.84 $\mathrm{kg} /$ litre, this corresponds to a fuel economy of 31.1 litres $/ 100 \mathrm{~km}$ over the full cycle.

\begin{tabular}{||l|r||}
\hline \hline Number of Cylinders & 6 \\
\hline Bore [mm] & 123 \\
\hline Stroke [mm] & 152 \\
\hline Compression ratio & 16 \\
\hline Swept Volume [1] & 11 \\
\hline
\end{tabular}

Table 6 - Basic engine data.

\begin{tabular}{||l|r||}
\hline \hline Weight $[\mathrm{kg}]$ & 10,950 \\
\hline Frontal Area $\left[\mathrm{m}^{2}\right]$ & 4.75 \\
\hline Drag Coefficient & 0.74 \\
\hline Tyre Rolling Radius [m] & 0.54 \\
\hline Final Drive Ratio & 5 \\
\hline Gearbox & Manual \\
\hline Number of ratios & 8 \\
\hline Gear. 1 Ratio & 17.7 \\
\hline Gear. 2 Ratio & 10.94 \\
\hline Gear. 3 Ratio & 6.57 \\
\hline Gear. 4 Ratio & 4.05 \\
\hline Gear. 5 Ratio & 2.54 \\
\hline Gear. 6 Ratio & 1.57 \\
\hline Gear. 7 Ratio & \\
\hline Gear. 8 Ratio & \\
\hline
\end{tabular}

Table 7 - Basic vehicle data. 


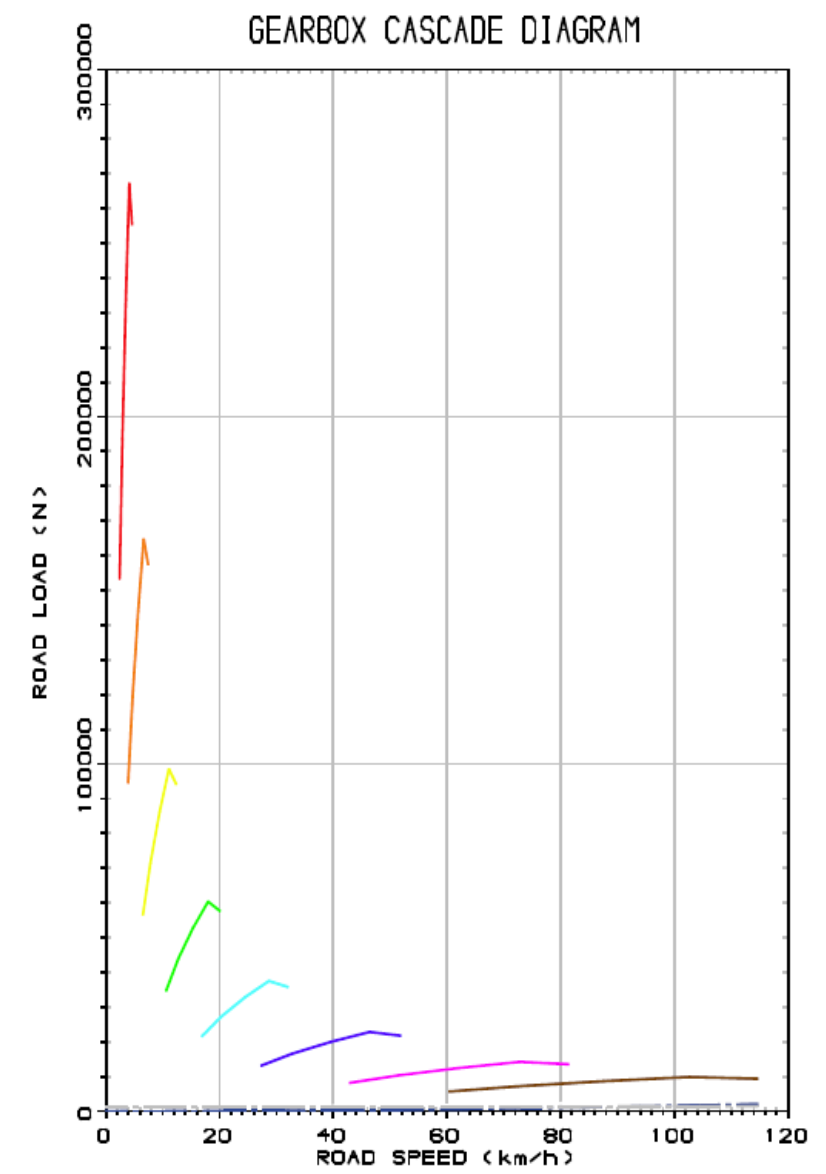

Table 8 - Tractive load diagram for the vehicle system at each drive ratio vs. the combined aerodynamic and tyre loads and vehicle speed (heavy duty diesel truck).

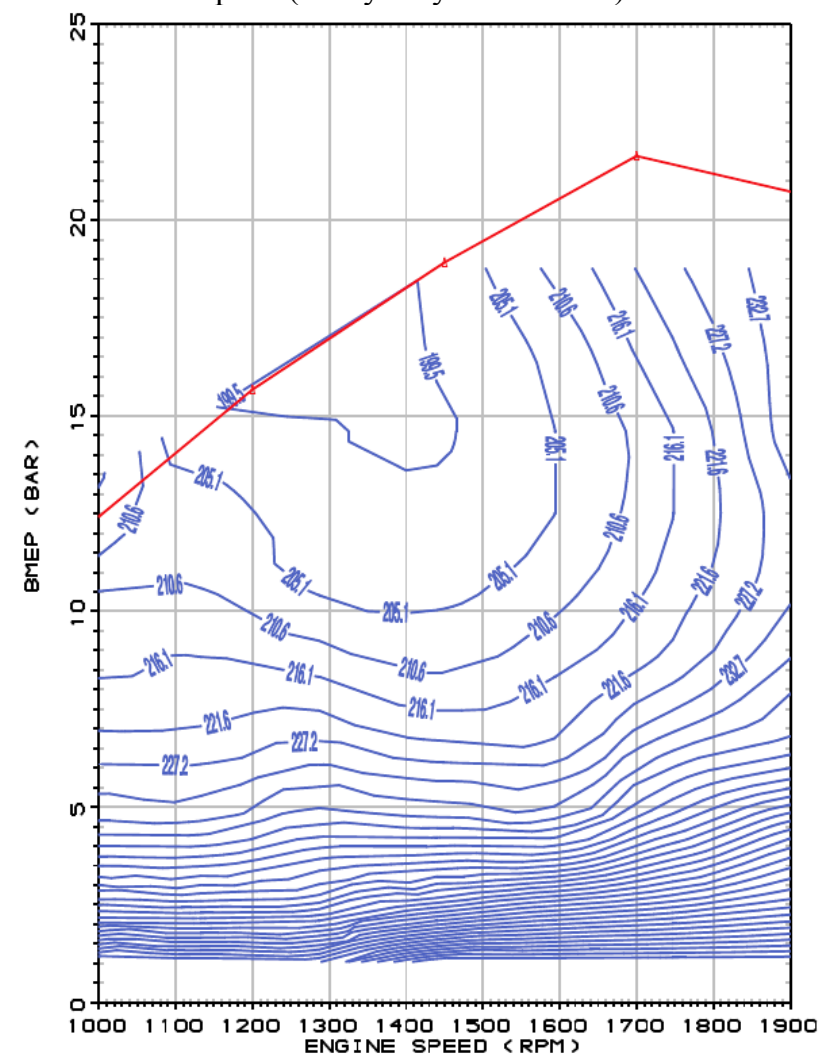

Figure 9 - Computed brake specific fuel consumption (in $\mathrm{g} / \mathrm{kWh}$ ) map for the 11TDI Diesel. 


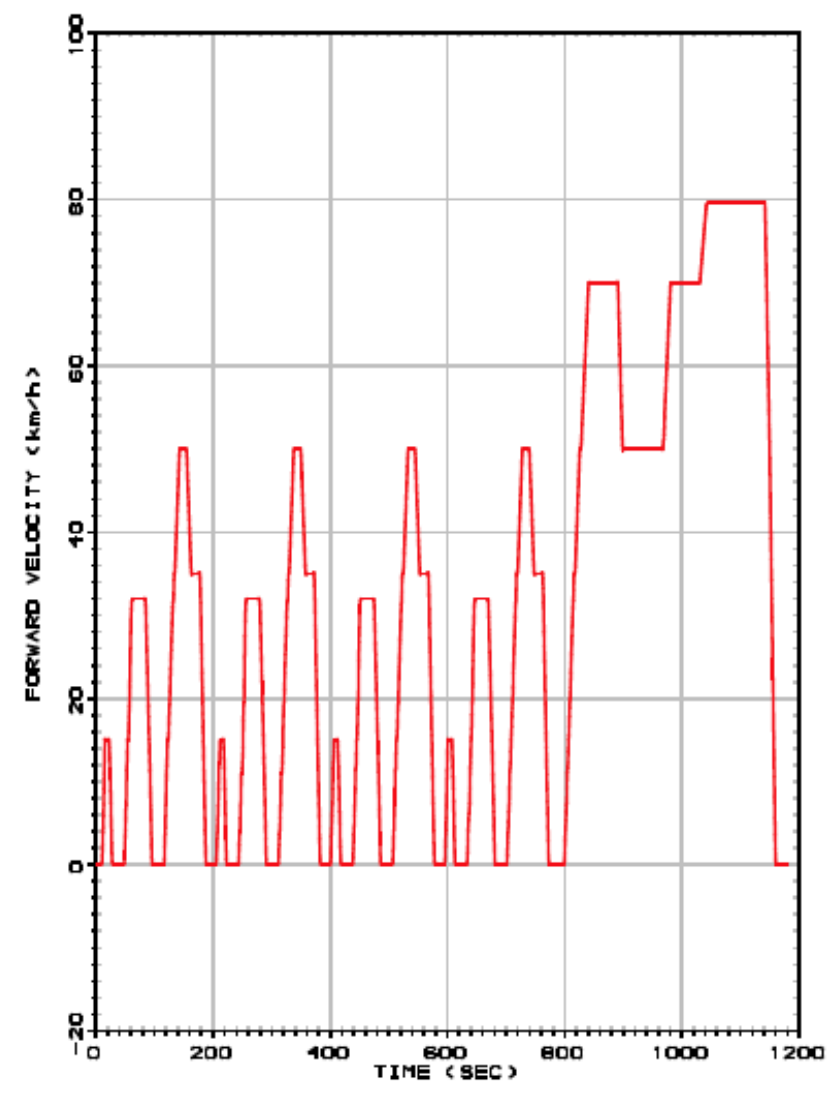

Figure 10 - Modified ECE+EUDC velocity schedule for fuel consumption of heavy duty trucks.

The larger efficiencies of the Diesel both top and part load resulting from the higher compression ratio, the turbo charging, the lean operation and the non throttled load control by quantity of fuel injected permits operation with large fuel efficiencies. A significant amount of energy used to accelerate the vehicle is then lost decelerating the vehicle.

The configuration with the 11TDI engine and KERS requires $2.15 \mathrm{~kg}$ of fuel to cover the full cycle. This corresponds to a fuel economy of 23.8 litres $/ 100 \mathrm{~km}$ over the full cycle with a fuel saving of $25 \%$.

In terms of miles per gallon US, the baseline configuration with an 11 litre engine and no KERS has a full cycle fuel economy of 7.56 mpgUS; the adoption of KERS increases the fuel economy to $9.88 \mathrm{mpgUS}$.

\section{CONCLUSIONS}

KERS based on a high speed flywheel and a constant variable transmission concept may permit efficient regenerative braking and torque assistance as a means of dramatically improving efficiency and hence reducing fuel consumption and $\mathrm{CO}_{2}$ emissions.

Computational models have been developed to compute the brake specific fuel consumption maps of one gasoline and one diesel passenger car engine and one truck engine, and the vehicle behaviour over the NEDC of two passenger cars and one truck.

Computational results show similar levels of fuel economy improvements of more than $25 \%$ over the NEDC for all the applications, passenger car or heavy duty trucks. Considering the large fuel cost of heavy transportation and the large production of carbon dioxide, the technique may deliver large improvements in fuel economy as well as much better emissions. Benefits of flywheel based KERS are similar to hydraulic regenerative braking but with the advantage of the reduced complexity and amount of space needed and the more simple construction and operation.

KERS have much faster charging and discharging rates than battery based regenerative systems (zero to full power in 50 ms). Therefore KERS have much better braking performances than battery based regenerative systems. Furthermore, the much simpler design and operation of KERS permits a much easier integration with the friction braking. 
Challenges to incorporate light and small volume KERS into passenger cars are expected to be minor, with reduction of system cost the major area of concern. Failure modes of concern including accident protection also need further investigation. Vehicle packaging and handling is more difficult for truck applications involving much larger power and torque.

The cost as well as the packaging and weight of a KERS for truck are not an issue as in passenger car applications. Two counter rotating flywheels could possibly solve stability issue due to the increased rotating mass required to brake vehicles of considerable weight. Energy boost by KERS may be beneficial more to help trucks climbing hills rather than for engine downsizing, also providing a better road safety. KERS will also collect considerable energy braking down hills reducing the need for engine brakes and thus noise.

\section{REFERENCES}

1. http://www.flybridsystems.com/Technology.html (retrieved January 8, 2010).

2. http://www.torotrak.com/IVT/works/ (retrieved January 8, 2010).

3. http://www.xtrac.com/pdfs/Torotrak_Xtrac_CVT.pdf (retrieved January 8, 2010).

4. http://www.bhr-technology.com/CPC-KERS.pps (retrieved January 8, 2010).

5. Stone, R., "Full-toroidal variable drive transmission systems in mechanical hybrid systems - from Formula 1 to road cars", CTI Symposium and Exhibition: Automotive Transmissions, Berlin, Germany, December 2009.

http://www.torotrak.com/Resources/Torotrak/Documents/Mech\%20hybrid\%20paper_CTI\%20Berlin09.pdf (retrieved January 11, 2010).

6. Body, W. and Brockbank, C., "Simulation of the fuel consumption benefits of various transmission arrangements and control strategies within a flywheel based mechanical hybrid system", VDI Transmissions in Vehicles Conference and Exhibition, Friedrichshafen, June 2009.

http://www.torotrak.com/Resources/Torotrak/Documents/VDI\%20Friedrichshafen\%202009.pdf (retrieved January 11, 2010).

7. Brockbank, C., and Greenwood, C., "Full-toroidal variable drive transmission systems in mechanical hybrid systems - from Formula 1 to road vehicles", CTI Symposium and Exhibition: Automotive Transmissions, Detroit, May 2009.

http://www.torotrak.com/Resources/Torotrak/Documents/CTI\%20Detroit\%20Paper\%202009.pdf (retrieved January 11, 2010).

8. Brockbank, C., "Application of a variable drive to supercharger and turbo compunder applications", SAE World Congress, Detroit, April 2009. 09PFL-0925

http://www.torotrak.com/Resources/Torotrak/Documents/SAE WC 2009 09PFL-0925 Variable Drive Boost System.pdf (retrieved January 11, 2010).

9. Brockbank, C., and Cross, D., "Mechanical hybrid system comprising a flywheel and CVT for motorsport and mainstream automotive applications”, SAE World Congress, Detroit, April 2009. 09PFL-0922.

http://www.torotrak.com/Resources/Torotrak/Documents/SAE WC 2009 09PFL-0922 KERS.pdf (retrieved January 11, 2010).

10. Brockbank, C. and Greenwood, C. , "Full-toroidal variable drive transmssion systems in mechanical hybrids - from Formula 1 to road vehicles", CTI Innovative Automotive Transmissions Conference and Exhibition, Berlin, December 2008.

http://www.torotrak.com/Resources/Torotrak/CTI_Berlin_2008.pdf (retrieved January 11, 2010).

11. Brockbank, C. and Greenwood, C. "Formula 1 mechanical hybrid applied to mainstream automotive", VDI Getriebe in Fahrzeuge Conference, June 2008.

http:/www.torotrak.com/Resources/Torotrak/VDI_2008.pdf (retrieved January 11, 2010).

12. http://www.ricardo.com/Documents/PRs\%20pdf/PRs\%202009/Ricardo\%20Kinergy\%20delivers\%20breakthrough\%20technolog y\%20low\%20cost $\% 20$ hybridisation.pdf (retrieved January 12, 2010).

13. http://www.ricardo.com/engb/Software/Productoffering--description/WAVE1/ (retrieved January 8, 2010).

14. http://www.lesoft.co.uk/index1.html (retrieved January 8, 2010).

15. www.unece.org/trans/doc/2003/wp29grpe/TRANS-WP29-GRPE-46-inf04e.pdf (retrieved April 1, 2010).

16. www.unece.org/trans/doc/2001/wp29grpe/TRANS-WP29-GRPE-41-inf01.pdf (retrieved April 1, 2010).

17. www.dieselnet.com/standards/cycles/whtc.php (retrieved April 1, 2010).

18. www.dieselnet.com/standards/cycles/whsc.php (retrieved April 1, 2010).

19. Matthew Barth, Theodore Younglove, George Scora, "Development of a Heavy-Duty Diesel Modal Emissions and Fuel Consumption Model”, California PATH Research Report UCB-ITS-PRR-2005-1. www.path.berkeley.edu/PATH/Publications/PDF/PRR/2005/PRR-2005-01.pdf (retrieved April 1, 2010).

20. NilsOlof Nylund, Kimmo Erkkilä, Nigel Clark and Greg Rideout, "Evaluation of duty cycles for heavy duty urban vehicles", Final report of IEA AMF Annex XXIX. www.vtt.fi/inf/pdf/tiedotteet/2007/T2396.pdf (retrieved April 1, 2010).

21. Coralie Cooper, Fanta Kamakaté, Thomas Reinhart, Matthew Kromer, Robert Wilson, "Reducing Heavy-Duty Long Haul Combination Truck Fuel Consumption and CO2 Emissions". Northeast States for Coordinated Air Use Management (NESCAUM) report. www.nescaum.org/documents/heavy-duty-truck-ghg_report_final-200910.pdf (retrieved April 1, 2010).

22. Carl Ensfield, L. Joseph Bachman, Anthony Erb, Cheryl Bynum, "Evaluating Real-World Fuel Economy on Heavy Duty Vehicles using a Portable Emissions Measurement System”, SAE P. 2006-01-3543. 
23. Cheryl Bynum, “Drive Cycle Development”. U.S. EPA (Environmental Protection Agency) report. www.epa.gov/smartway/documents/drive-cycle-development.pdf (retrieved April 1, 2010).

28. U.S. EPA (Environmental Protection Agency), "SmartWay Fuel Efficiency Test Protocol for Medium and Heavy Duty Vehicles". www.epa.gov/smartway/documents/420p07003.pdf (retrieved April 1, 2010).

29. Michael Bassett, "Investigation of Technologies to Improve Drive-cycle Fuel Economy”. http://www.lesoft.co.uk/files/Hyb_Veh_2005.pdf (retrieved May 25, 2010).

\section{APPENDIX}

\begin{tabular}{||c|c||}
\hline power (set by FIA rules) [KW] & 60 \\
\hline Torque [N·m] & 18 \\
\hline Energy Transfer per lap (set by FIA rules) [kJ] & 400 \\
\hline System Weight [kg] & 25 \\
\hline Flywheel weight [kg] & 5 \\
\hline CVT weight [kg] & 5 \\
\hline Flywheel Diameter [m] & 0.2 \\
\hline Flywheel Length [m] & 0.1 \\
\hline Efficiency round trip [\%] & $>70$ \\
\hline
\end{tabular}

Table A1 - Parameters of the Flybrid F1 KERS [6-8, 10] 